\title{
Mechanical Properties of Fibre Reinforced Geopolymer Composites Exposed to Operating Fluids
}

\author{
HRON Robin, KADLEC Martin \\ Strength of Structure \\ VZLU - Czech Aerospace Research Centre \\ Prague, Czech republic \\ e-mail: hron@vzlu.cz, kadlec@vzlu.cz
}

\author{
MARTAUS František \\ Composite Technologies \\ VZLU - Czech Aerospace Research Centre \\ Prague, Czech republic \\ e-mail: martaus@vzlu.cz
}

\begin{abstract}
Geopolymers are amorphous aluminosilicate materials which combine low temperature, polymer-like processing with high temperature stability and fire resistibility without toxic smoke generation. For larger expansion of geopolymer composites in aircraft industry, it is necessary to know how it behaves in contact with operating fluids. The specimens were divided into groups exposed to fuel, hydraulic oil, jet oil, and salt mist. Hot/Wet condition until saturation was also applied for one group. Mechanical testing was performed by means of tension, compression, in-plane shear, flexion and interlaminar shear on both reference non-treated and exposed specimens. The largest decrease in all measured strength values was caused by the salt mist. As the most significant, in-plane shear strength was decreased by $85 \%$ by this environment. Operating fluids and hot/wet conditions decreased the shear strength approx. by $15 \%$. Geopolymer composites are an interesting alternative to existing polymeric and ceramic matrix materials and offers high potential for cost-efficient applications dealing with temperatures up to $1200^{\circ} \mathrm{C}$.
\end{abstract}

Keywords: composite; geopolymer; environment; mechanical properties.

\section{INTRODUCTION}

The expression „Geopolymer" has its root in raw materials used in the first synthesis of silicon-based polymers, the origin of which were mainly rock-forming minerals. Joseph Davidovits coined the term in 1978 [1]. Geopolymers are amorphous aluminosilicate materials (also referred to as inorganic aluminosilicate polymers) [2]. Geopolymer have excellent temperature stability and fire resistance (Figure 1) with no generation of toxic fumes and smokes have also low thermal conductivity, good specific strength and low price [3]. The geopolymer behaves like a ceramic, but does not require high proceeding temperatures or pressures, so it can be worked up like common organic resins [4].

At the present, there is increasing need for materials eliminating fatal results of fire in case of aircraft accident [5, 6]. The geopolymers seems to be a good choice. That's a reason why the authors have done a numbers of experiments in the past, e.g. [7-9]. For larger expansion of geopolymer composites in aircraft industry, it is necessary to know how it behaves in contact with operating fluids and that is the task of this experiment.

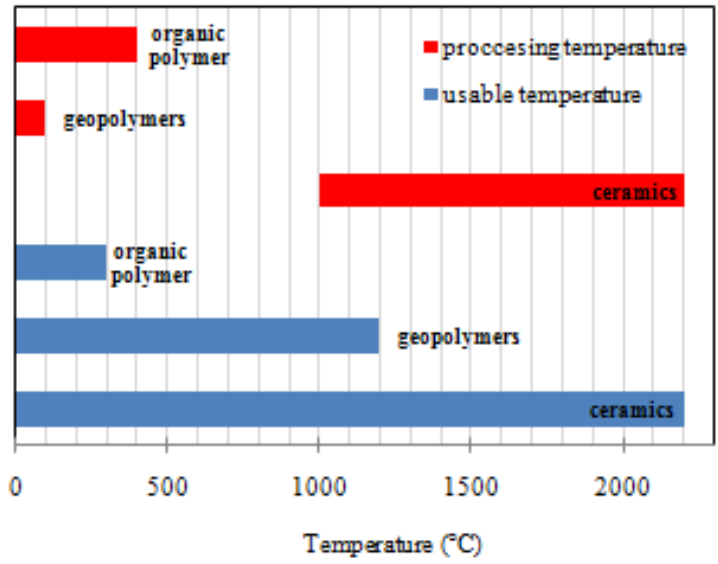

Figure 1. Processing and usable temperatures of composite matrixes

\section{EXPERIMENT}

The effect of exposure to the mechanical properties of the geocomposite was examined. Tensile test per ASTM D3039, compression test per ASTM D6641, in-plane shear (IPS) test per ASTM D3518, flexural test per ISO 14125 and interlaminar shear strength (ILSS) test per ASTM D2344 were carried out. Half of the tests was performed on test samples at room temperature, with no previous exposure (REF) and the second half with previous exposure to operating fluids: fuel $(\mathrm{F})$, hydraulic oil (HO), jet oil (JO) and in salt mist (SM) and "hot-wet" (H/W) conditions. Total of 146 samples were tested.

\section{A. Material}

For tensile, compression, flexural and interlaminar tests samples were used unidirectional carbon fibre tape, type TCU175, 3K [10] and for in-plane shear test samples were used multiaxial knitted carbon fabric $200 \mathrm{~g} / \mathrm{m}^{2}, 12 \mathrm{k}$ [11]. For all specimens, a geopolymer resin GPL 30 [9] was used.

\section{B. Test Samples}

Test panel were prepared by contact laminating (standardly $400 \mathrm{~g}$ of resin/ $\mathrm{m}^{2}$ of fabric). Parameters of the curing cycle: heat up rate $2-8^{\circ} \mathrm{C} / \mathrm{min}$, cured temperature 
$85 \pm 3^{\circ} \mathrm{C}$, dwell time 18 hours, vacuum min. $-80 \mathrm{kPa}$, cooling rate $\max .8^{\circ} \mathrm{C} / \mathrm{min}$. Test samples were cut from the test panel by a diamond blade.

The surface protection of all test samples to improve the resistance to external influence (especially by water) was performed by immersing test samples into a mixture of ethyl silicates of polysilic acids, concurrently with Dynasylan Silbond 40 [12].

TABLE I. TEST MATRIX, WITH THE NUMBERS OF THE SAMPLES

\begin{tabular}{|c|c|c|c|c|c|c|}
\hline \multirow{2}{*}{$\begin{array}{c}\text { Test } \\
\text { Type }\end{array}$} & no exposure & \multicolumn{5}{|c|}{ exposure in } \\
\cline { 2 - 7 } & $\boldsymbol{R E F}$ & $\boldsymbol{F}$ & $\boldsymbol{J O}$ & $\boldsymbol{H O}$ & $\boldsymbol{H W}$ & $\boldsymbol{S M}$ \\
\hline IPS & 6 & 5 & 5 & 5 & 5 & 5 \\
\hline Tension & 5 & 5 & 5 & 5 & 4 & 5 \\
\hline Compression & 6 & 5 & 5 & 5 & 5 & 5 \\
\hline Flexural & 5 & 4 & 5 & 5 & 5 & 3 \\
\hline ILSS & 5 & 5 & 5 & 5 & 5 & 3 \\
\hline
\end{tabular}

\section{Exposure at Environmental}

The specimens were divided into groups (see TABLE I) and exposed, with respect of EN ISO 175, for 14 days in aviation fuel - Jet A-1 (F) [13], gas aircraft turbine lubricant - Mobil Jet Oil II (JO) [14], hydraulic oil - AeroShell Fluid 41 (HO) [15]. One test set was exposed in salt mist (SM) with concentration of the $\mathrm{NaCl}$ solution $50 \mathrm{~g} / \mathrm{l}$, temperature $35^{\circ} \mathrm{C}$ and relative humidity $100 \%$, exposure was performed according to standard EN ISO 9227. Hot/Wet (HW) condition until saturation, per EN 60068-2-78, was also applied for one group.

\section{Tests}

All tests were performed in the testing laboratory of Strength of structure department of the Czech aerospace research centre according to valid standards on the static test machine Instron 55R1185.

1) Tensile test: performed according to ASTM D3039 standard. All specimens were placed in the grips of the testing machine, taking care to align the long axis of the gripped specimen with the test direction. Speed of testing was set on $2 \mathrm{~mm} / \mathrm{min}$. Due to the requirement for tensile modulus and Poisson's ratio measurement biaxial extensometer Epsilon-BIA-025M-010-ST (gauge length $25 \mathrm{~mm}$ ) was attached on the tests samples. The test assembly is shown in Figure 2.

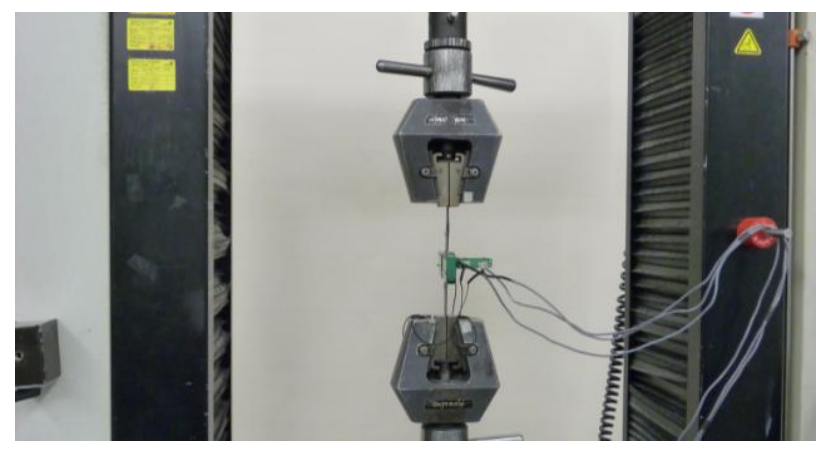

Figure 2. Tensile test - setup

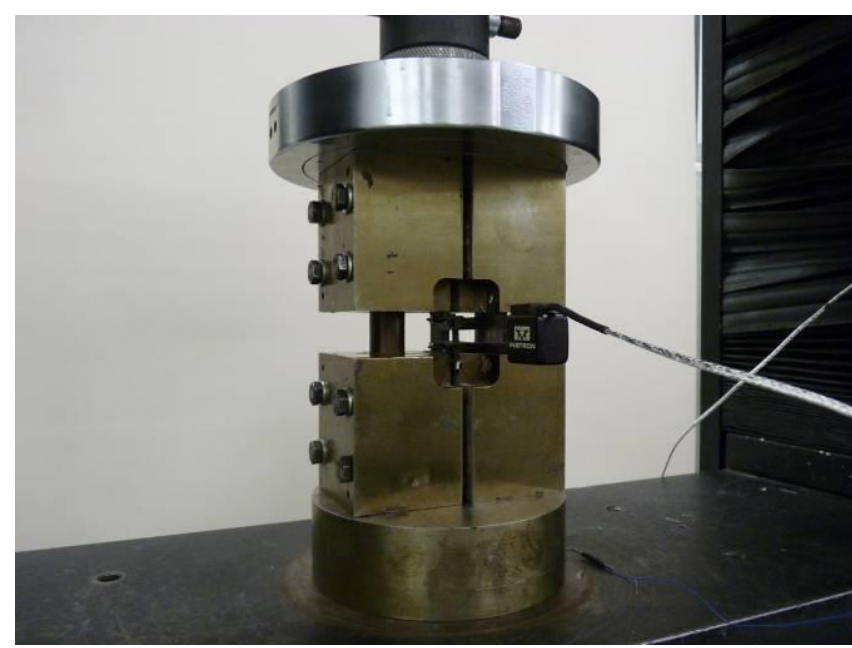

Figure 3. Compression test - setup

2) Compression test: performed according to ASTM D6641. Specimen was fixed in the combined loading compression (CLC) test fixture so that the end of the specimen was in flush with the ends of the CLC test fixture. All screws on the CLC fixture were screwed to $2.5 \mathrm{Nm}$. The assembled fixture was placed between well-aligned, fixed flat platens (platen surfaces parallel was within $0.03 \mathrm{~mm}$ across the fixture base). To determine the compression modulus of the geopolymer, extensometer Instron 2620-601 with gauge length $12.5 \mathrm{~mm}$ was attached on the test sample. The test assembly is shown in Figure 3.

3) Flexural test: performed according to ISO 14125 standard. Span length was set such that the span-tothickness ratio was 16 with an accuracy $\pm 0.3 \mathrm{~mm}$. Test sample was inserted into the test fixture such that its longitudinal axis was perpendicular to the loading nose and supports. The diameter of loading nose and supports was $5 \mathrm{~mm}$. For flexural modulus measuring the extensometer Instron 2620-601 with gauge length $50 \mathrm{~mm}$ was attached to the fixture.

4) In-plane shear test (IPS): performed according to ASTM D3518. Sample was placed into the grips such that the longitudinal axis of the test sample was in the test direction. Speed of testing was set on $2 \mathrm{~mm} / \mathrm{min}$. Due to the character of the test where axial and transverse strain during the test must be measured, biaxial extensometer Epsilon BIA-025M-010-ST with gauge length $25 \mathrm{~mm}$ was attached on the sample.

5) Interlaminar shear strength (ILSS): performed according to ASTM D2344. Specimens were inserted into the test fixture that the longitudinal axis were perpendicular to the loading nose and supports. Loading Nose and Supports, was $6.0 \mathrm{~mm}$ respectively $3.0 \mathrm{~mm}$ diameter cylinders. Speed of testing was set on $1.0 \mathrm{~mm} / \mathrm{min}$. 


\section{RESULTS}

All measured results were tested by Dixon's Q test on presence of outliers. Test was performed for significance level 0.05 . In total approximately $3 \%$ from all results were excluded. Outlying values were not included into the test evaluation. A T-test for determination if the individual sets are significantly different from each other was performed, see TABLE II. Statistical significance 0.05 was chosen. The measured values of averages strengths with standard deviations are shown in Figures 5, 7 and 8.

\section{A. Shear properties}

1) In-plane shear strength: Referenced set showed the highest average IPS strength: 21.6 MPa. The lowest average IPS strength was measured on the samples which were exposed in salt milt: $3.3 \mathrm{MPa}$. Based on the statistical evaluation it can be said that the sets F and JO did not show statistically significant lower values than the reference set. Average IPS strength was $19.7 \mathrm{MPa}$ for set $\mathrm{F}$ and 19.9 for set JO.

2) Shear modulus: Highest shear modulus of elasticity (G) was measured on the reference set, $G_{\mathrm{REF}}=5.97 \mathrm{GPa}$. The lowest modulus showed the samples which were exposed in salt mist. The $\mathrm{G}$ modulus of these samples was extremely low: $0.4 \mathrm{GPa}$. Comparing with the reference set, a statistically significant difference in the mean value of the $G$ modulus was found for all five sets. Typical failure mode is shown in Figure 4.

3) Interlaminar shear strength: The highest interlaminar shear strength (ILSS) was measured on the reference samples. Average value of ILSS was 16.6 MPa. The lowest values of ILSS strength were measured on SM samples. Average ILSS of the sets F, JO and HO was not significantly different from the reference one.

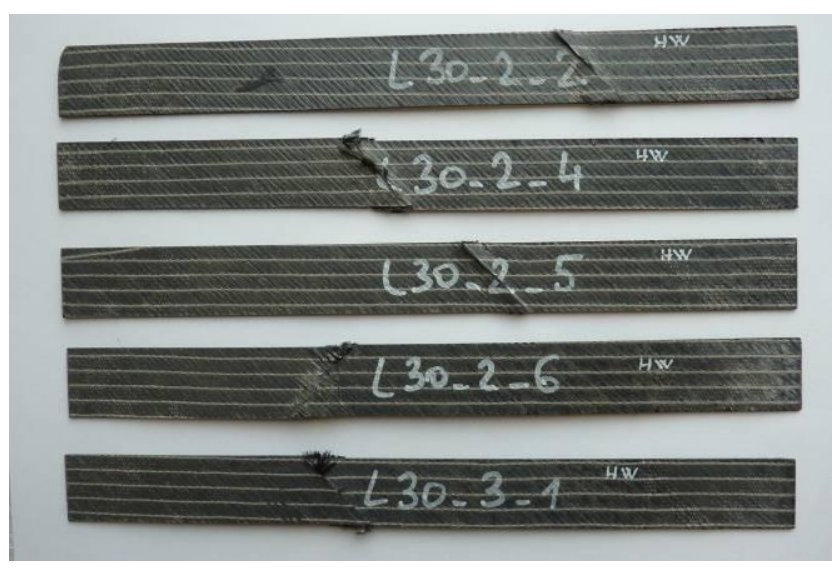

Figure 4. Typical shear failure, IPS HW samples

\section{B. Tensile properties}

1) Tensile strength: For the reference set, an average tensile strength of $415.1 \mathrm{MPa}$ was measured. The higher average strength showed the HW set: $447.4 \mathrm{MPa}$, but this set had also the highest coefficient of variation (C.V.): $14 \%$. On the reference set, the C.V was. 5\%. The lower strength was measured on the test samples which were exposed in salt mist. The statistical evaluation showed the correspondence only between the reference set and the HW set. Typical failure mode is shown in Figure 6.

2) Tensile modulus: With comparison of the referenced set, a statistically not significant different of average tensile modulus of elasticity $\left(\mathrm{E}^{\mathrm{T}}\right)$ was measured only on the set HW. $\mathrm{E}^{\mathrm{T}}{ }_{\text {REF }}=85.6 \mathrm{GPa}$ and $\mathrm{E}^{\mathrm{T}}{ }_{\mathrm{HW}}=84.5 \mathrm{GPa}$.

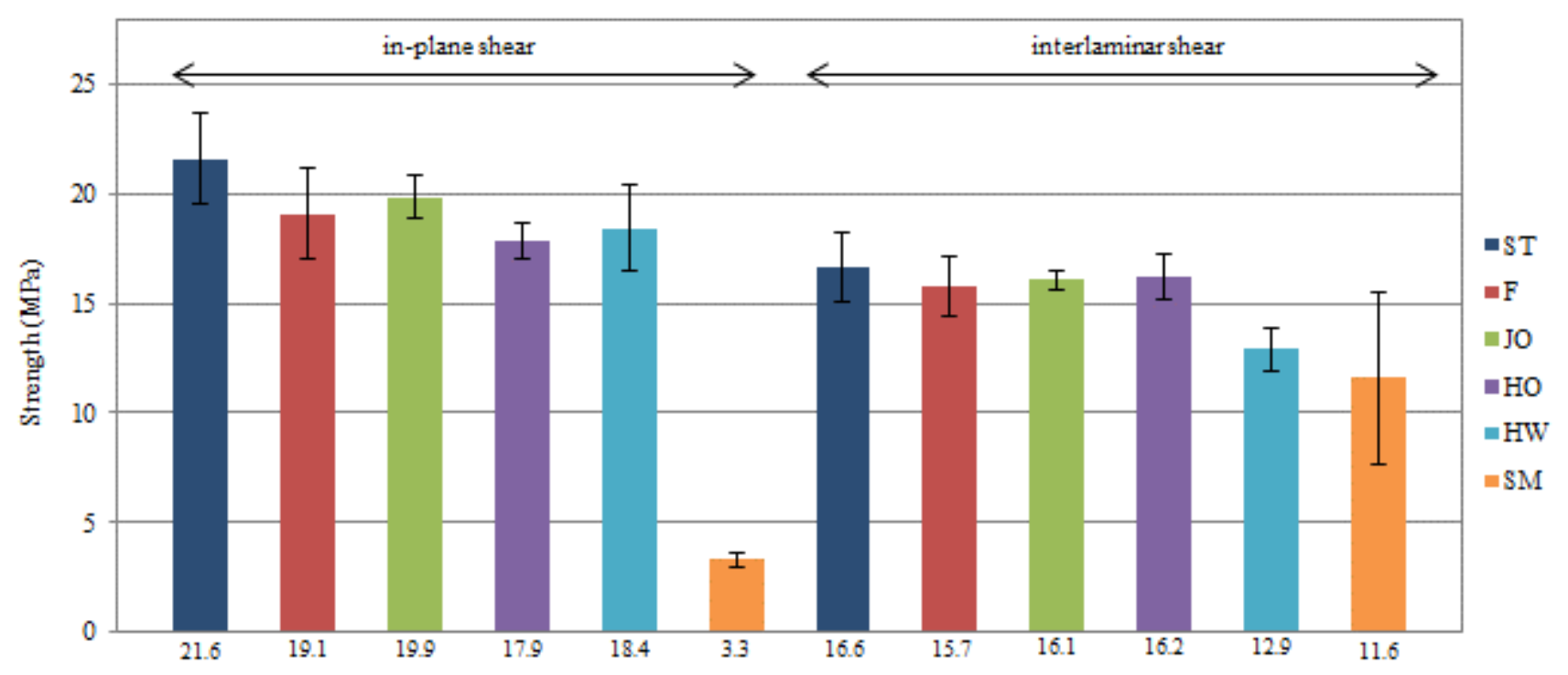

Figure 5. Average values of measured shear strength. 


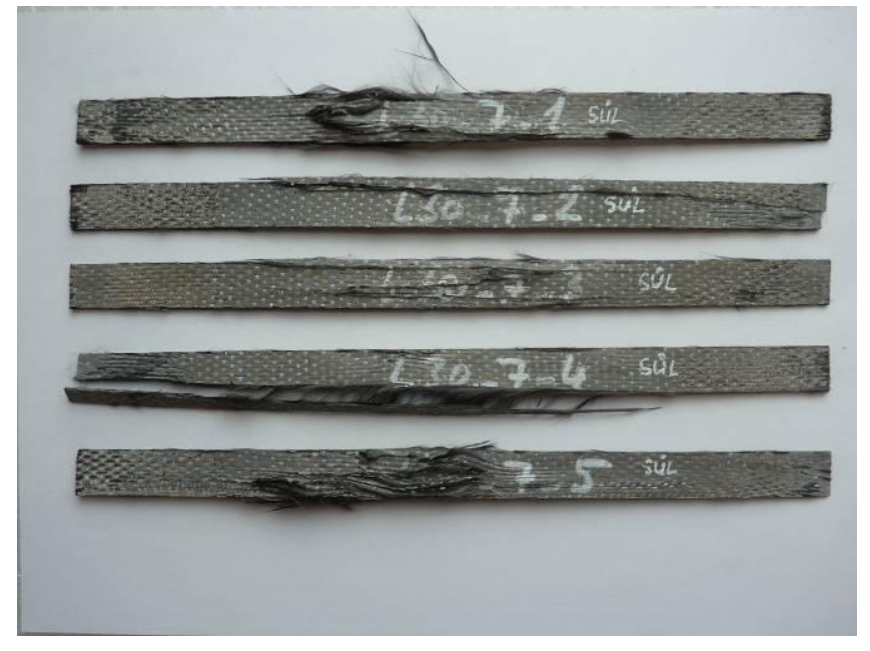

Figure 6. Typical tensile failure, SM samples

\section{Compressive properties}

1) Compressive strength: The reference set showed the highest compressive strength: $225.5 \mathrm{MPa}$. The statistical evaluation showed that the difference between this value and the values measured on the sets F (215.4 MPa), JO (206.3 MPa) and HO (209.12 MPa) is statistically insignificant. The lowest average strength 168.1 MPa was measured on the set HW.

2) Compressive modulus: On the reference set was measured average compressive modulus of elasticity, $\mathrm{E}_{\text {REF }}^{\mathrm{C}}$ $=96.8 \mathrm{GPa}$. Sets JO $\left(\mathrm{E}_{\mathrm{JO}}^{\mathrm{C}}=91.1 \mathrm{GPa}\right), \mathrm{HW}\left(\mathrm{E}_{\mathrm{HW}}^{\mathrm{C}}=83.0\right.$ $\mathrm{GPa})$ and $\mathrm{SM}\left(\mathrm{E}_{\mathrm{SM}}^{\mathrm{C}}=86.5 \mathrm{GPa}\right)$ showed statistically not significant difference.
TABLE II. COMPARISON OF THE MEASURED PROPETIES; ND STATISTICALY NOT SIGNIFICANTLY DIFFERENT, D - STATISTICALLY DIFFERENT

\begin{tabular}{|c|c|c|c|c|c|}
\hline & \multicolumn{5}{|c|}{ REF compared with } \\
\cline { 2 - 6 } & $\boldsymbol{F}$ & $\boldsymbol{J} \boldsymbol{H}$ & $\boldsymbol{H} \boldsymbol{H}$ & $\boldsymbol{H} \boldsymbol{W}$ & $\boldsymbol{S}$ \\
\hline $\begin{array}{c}\text { In-plane } \\
\text { shear strength }\end{array}$ & $\mathrm{ND}$ & $\mathrm{ND}$ & $\mathrm{D}$ & $\mathrm{D}$ & $\mathrm{D}$ \\
\hline $\begin{array}{c}\text { Shear } \\
\text { modulus }\end{array}$ & $\mathrm{D}$ & $\mathrm{D}$ & $\mathrm{D}$ & $\mathrm{D}$ & $\mathrm{D}$ \\
\hline $\begin{array}{c}\text { Interlaminar } \\
\text { shear strength }\end{array}$ & $\mathrm{ND}$ & $\mathrm{ND}$ & $\mathrm{ND}$ & $\mathrm{D}$ & $\mathrm{D}$ \\
\hline $\begin{array}{c}\text { Tensile } \\
\text { strength }\end{array}$ & $\mathrm{D}$ & $\mathrm{D}$ & $\mathrm{D}$ & $\mathrm{ND}$ & $\mathrm{D}$ \\
\hline $\begin{array}{c}\text { Tensile } \\
\text { modulus }\end{array}$ & $\mathrm{D}$ & $\mathrm{D}$ & $\mathrm{D}$ & $\mathrm{ND}$ & $\mathrm{D}$ \\
\hline $\begin{array}{c}\text { Compression } \\
\text { strength }\end{array}$ & $\mathrm{ND}$ & $\mathrm{ND}$ & $\mathrm{ND}$ & $\mathrm{D}$ & $\mathrm{D}$ \\
\hline $\begin{array}{c}\text { Compression } \\
\text { modulus }\end{array}$ & $\mathrm{D}$ & $\mathrm{ND}$ & $\mathrm{D}$ & $\mathrm{ND}$ & $\mathrm{ND}$ \\
\hline $\begin{array}{c}\text { Flexural } \\
\text { strength }\end{array}$ & $\mathrm{ND}$ & $\mathrm{ND}$ & $\mathrm{ND}$ & $\mathrm{D}$ & $\mathrm{D}$ \\
\hline $\begin{array}{c}\text { Flexural } \\
\text { modulus }\end{array}$ & $\mathrm{ND}$ & $\mathrm{ND}$ & $\mathrm{ND}$ & $\mathrm{ND}$ & $\mathrm{D}$ \\
\hline
\end{tabular}

\section{Flexural properties}

1) Flexural strength: On the reference samples, the highest flexural strength was measured: $337.2 \mathrm{MPa}$. Statistically insignificant different was measured on sets $\mathrm{F}$ (306.6 MPa), JO (308.7 MPA) and HO (329.0 MPa). Lowest average flexural strength was measured on the set $\mathrm{SM}$ (168.7 MPa).

2) Flexural modulus: Highest flexural modulus was measured on the reference set $(65.8 \mathrm{GPa})$, lowest on the SM set $(40.2 \mathrm{GPa})$. Only this lowest flexural modulus showed statistically significant difference of average flexural modulus with comparison of referenced set.

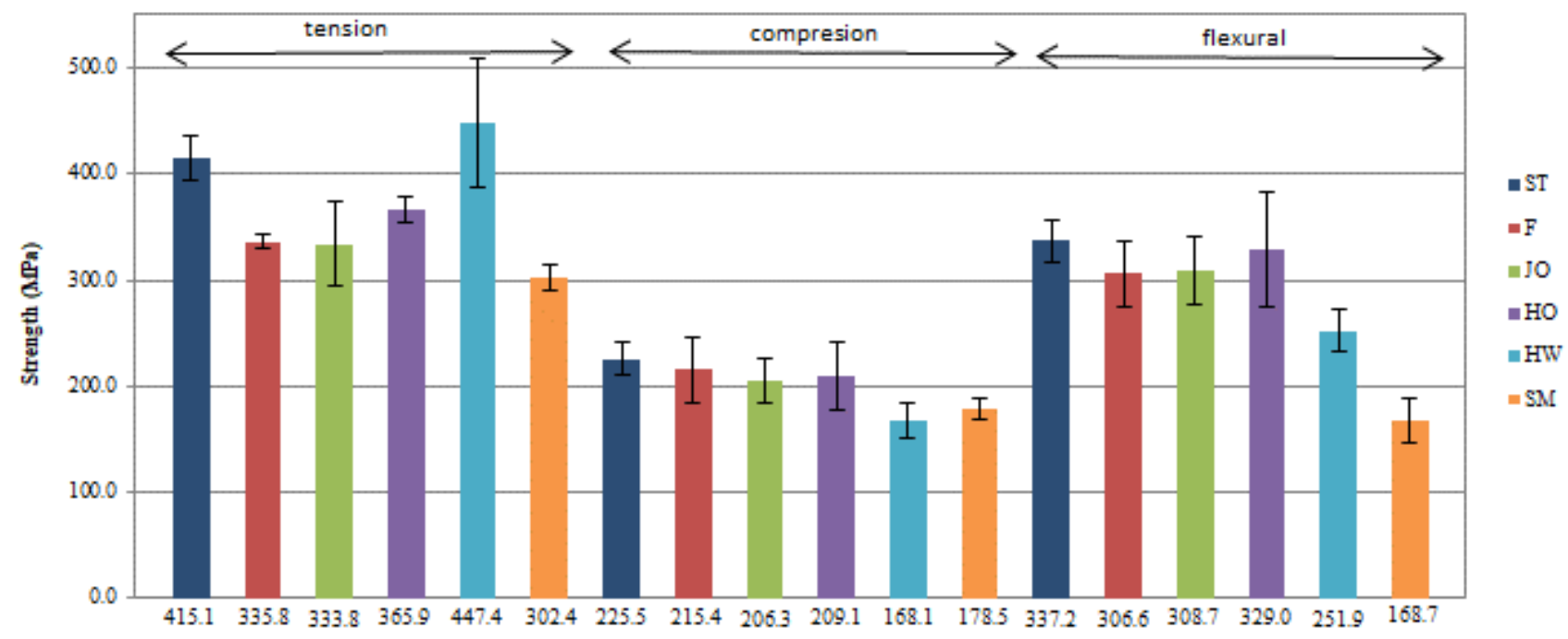

Figure 7. Average values of measured tensile, compressive and flexural strengths. 


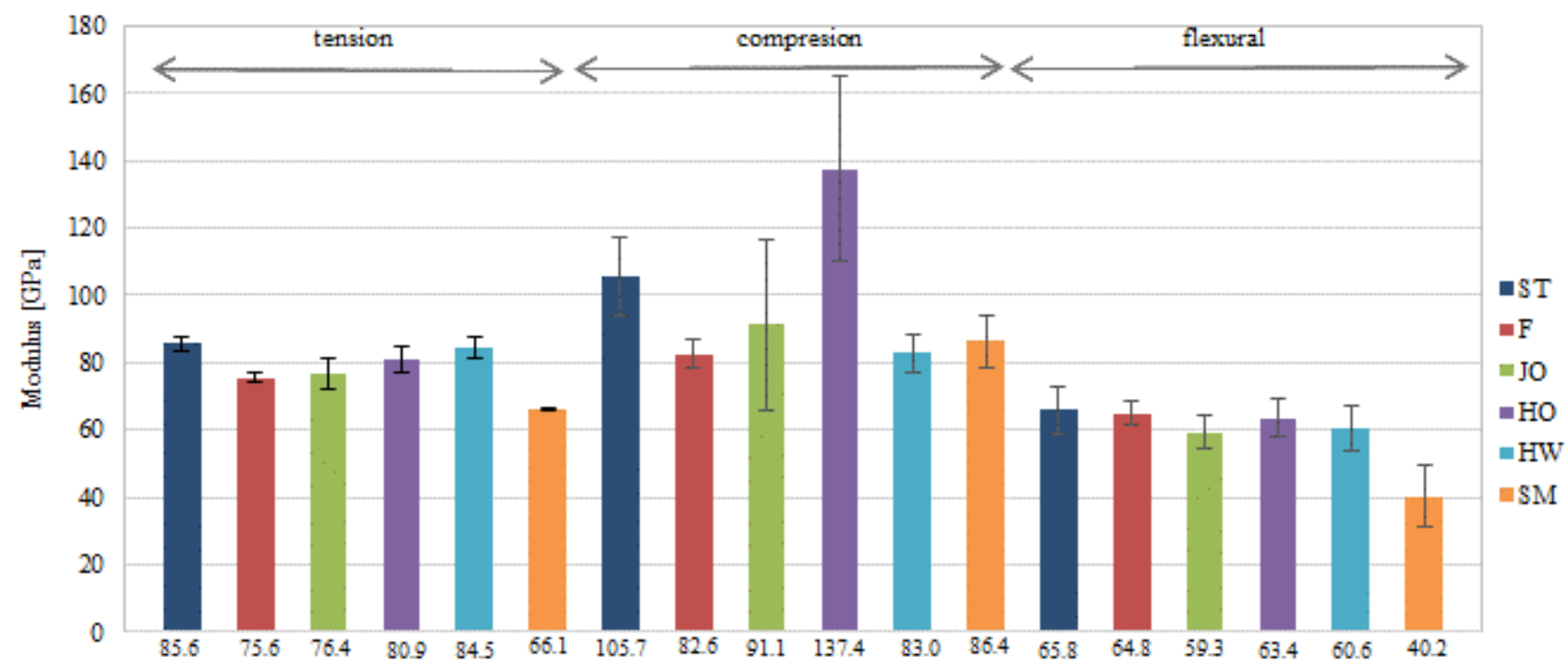

Figure 8. Average values of measured tensile, compressive and flexural modulus.

\section{CONCLUSION}

The material tests showed the significant influence of the environment on the material characteristics of the studied geopolymer material and it is therefore necessary to consider this when designing structures. The greatest negative impact was measured on samples which were exposed in salt mist (SM). The average shear strength in SM was $85 \%$ lower than the average shear strength of the reference set. The measured material properties on SM set were, except the compressive modulus, always statistically significantly different from the material properties measured on the reference set. Exposition to the aircraft fuel and to the gas aircraft turbine lubricant had significant effect only on the tensile strength that showed a significant decrease by $20 \%$. The hydraulic oil had significant effect on IPS strength (17\%) and tensile strength (12\%) and the Hot/Wet conditions significantly decreased all strength values except the tensile strength (up to $25 \%$ ). This research can help to select the geopolymer materials considering the application in the extreme environment.

\section{ACKNOWLEDGMENT}

This research was prepared in the frame of "Future Sky Safety" project, the Joint Research Initiative Safety P7, project "Mitigate risk of fire, smoke and fumes".

\section{REFERENCES}

[1] J. Davidovits, "Geopolymers: Inorganic Polymeric New materials," J. Thermal Analysis, 37, pp. 1633-1756, 1991

[2] Engineered material handbook, Vol. 1., COMPOSITE, ASM International, Metals Park, OH, 1987.

[3] J. Davidovits, Geopolymer Chemistry \& Applications, Institute Géopolymèr, France, 2008.

[4] J. Davidovits, 30 Years of Successes and Failures in Geopolymer Applications - Market trends and Potential breakthroughs. Geopolymer 2002 Conference, Melbourne,Australia, Geopolymer Institute, pp. 1-16, 2002.

[5] Richard E. Lyon, Fire Response of Geopolymer Structural Composites, DOT/FAA/AR-TN95/22, 1996

[6] Richard E. Lyon, "Fire Safe Aircraft Cabin Materials," in Fire and Polymers, ACS Symposium Series Number 599, G.L. Nelson, ed., American Chemical Society, Washington, D.C., p. 618, 1995.

[7] Martaus. F., R-6727 Geopolymer Composites Future Sky, Czech Aerospace Research Centre, 2015.

[8] Martaus. F., R-6727 Mechanical Properties of Geopolymers - Resin I, Czech Aerospace Research Centre, 2016.

[9] Martaus. F., R-6375 Geopolymer resins, Czech Aerospace Research Centre, 2016.

[10] G. Angeloni, Woven UD tape TCU 175, Product Data Sheet, 2012.

[11] Fabrics for composites, Multiaxial knitted fabric MC-45C-0200, Product Data Sheet, 2014.

[12] Evonik Industries AG, Dynasylan 40, Product Data Sheet, 2011.

[13] Petro Star Inc., Jet A or Jet A-1 Aviation Fuel, Product Specification Sheet,2014.

[14] Mobil, Mobil Jet Oil II, Product data sheet,

[15] Shell, AeroShell Fluin 41, Technical Data Sheet. 